\title{
WATER INFRASTRUCTURE MAINTAINABILITY - ISSUES AND CHALLENGES IN THE COASTAL REGIONS OF AKWA IBOM STATE
}

\author{
B. B. Okon ${ }^{1, *}$, V. E. Okon ${ }^{2}$ and E. J. Udom ${ }^{3}$

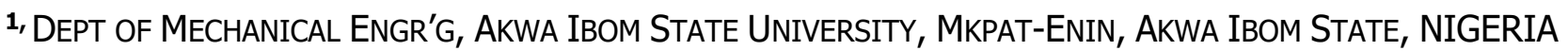 \\ 2, College of EngR'G \& TECH., Micheal OKPARA Univ. Of AgriCUlture, UMUdike, ABIA STATE, NIGERIA \\ 3, DePARTMENT OF MECHANICAL ENGINEERING, UNIVERSITY OF IBADAN, IBADAN, OYO STATE, NIGERIA \\ Email addresses: ${ }^{1}$ engrbasseyokon@gmail.com, ${ }^{2}$ engrvik@gmail.com, ${ }^{3}$ udomevans@yahoo.com
}

\begin{abstract}
In this study, incessant collapse of water infrastructure along with shortage of water supply from public mains due to poor maintenance culture within the coastal areas of Akwa Ibom State are the key issues and challenges associated with the performance of water infrastructure in the area under consideration. These indices have been of great concern to building services engineers, estate managers and other stakeholders within the built environment. With the option of continuous (periodic) and practical maintenance culture as a panacea, effective water supply is guaranteed. This study has established better ways of tackling these problems (indicative risks) concerning maintainability of water infrastructure for optimum service delivery. Qualitative analyses were performed on air and water samples collected within the affected water infrastructure environment. In this case, concrete water stanchions (CWS) and steel water stanchions (SWS) along with the mechanical systems: submersible pumps, control valves performance were also evaluated to ascertain the level of environmental damages meted on the water works over a period of time upon commissioning and use. From the achievable tests, it is evident that the pH (-) results are higher in the investigated CWS than SWS except the turbidity results which are at par. These results have demonstrated that CWS is preferable to SWS for ease of periodic maintenance.
\end{abstract}

Keywords: Concrete stanchion, environment, maintenance, mechanical systems, steel stanchion

\section{INTRODUCTION}

Water infrastructure is a typical basic necessity in the society meant to provide services delivery and comfort in various dimensions for economic growth [1]. The structure (stanchion) often provides the physical framework in which water storage tanks (reservoirs) rest upon in order to deliver water for domestic consumption, industrial and irrigation purposes among other activities [2]. In parts of the water network, there are many conditions that may contribute to the deterioration of water quality and often failure of water stanchion or the entire system. For proper maintenance of facility, the networks are often designed and operated to prevent ingress of contaminants and disinfectant concentrations within a predetermined range. The proper management and maintenance of this infrastructure is of immense importance for optimum service delivery $[3,4]$.

\subsection{Water sources, pumping operation and performance}

For an appropriate water infrastructure, the source of water must be identified. In the study area, the sources of water available for consumption are wells, ponds, streams and rivers. These water bodies are predominantly brackish (saline) in nature and sometimes far away from the residential areas. Equally, water mains connected from public supply are dry, thus prompting the inhabitants to root for alternative source which is borehole. This requires some rotor dynamic machines which are mostly preferred in water pumping applications because of

* Corresponding author, tel: $+234-803-799-9152$ 
their mechanical simplicity and lower capital or operating costs for pumping operations [5]. The activities associated with pumping water from a raw source involves water travelling from the supply to slake (lime) room where lime is picked up in order to check its $\mathrm{pH}$ level [6] and then moves to filter beds where iron and other impurities are removed from water through oxidation and filtration processes. The filtered water is then moved to chlorination chamber where chloride ion is injected into the water for disinfection. Finally, the chlorinated water is then discharged to the storage system (reservoir) and further delivered into the mains, supply and distribution lines for final consumption [6].

\subsection{Study area}

In this study, Mbo, ONNA, Eket, Ibeno, Ikot-Abasi, Mkpat Enin and Eastern Obolo Local Government Areas and other adjoining towns in Akwa Ibom State of Nigeria, were considered as constituting the study area. This area comprises of core oil producing communities in the state, with a proximate population of 1.4 million and a coordinate between $4.50^{\circ} \mathrm{N}$ and $8.26^{\circ} \mathrm{E}$ [7]. The rainy period in this region is usually between April and October, interrupted by a short break in August yearly. In addition, the average annual rainfall in this case is between 2000 and 4000 $\mathrm{mm}$ while the relative humidity varies between 53 and $91 \%$ with the mean annual temperature of about 28 and $33^{\circ} \mathrm{C}$. The considered study area was chosen as a result of incessant dark discolouration, corrosive effects and general failure observed on CWS and the SWS therein, which in turn have reduced the aesthetic and economic value of the infrastructure systems [7].

\section{RESEARCH DESIGN}

This study was designed with a focus on gathering measured field samples from sites where CWS and the SWS are located within the studied locations. Accordingly, effort was made in appraising the mechanical systems (submersible pumps, control valves) and other accessories performance along with the maintainability (periodic maintenance) of the studied water stanchions for the period of one year after commissioning and use. Also captured are environmental factors that could possibly affect the longevity of water stanchions performance and other elements associated with water quality and distribution networks. To achieve this study aim, sixteen factors were identified and samples collected at different locations for analysis.

\subsection{Major issues}

Problems such as poor site survey and erroneous design, poor material selection with wrong construction method have primary deleterious effect on water infrastructure [8]. It is noted that client's inclination in the award of contract as well as shortage of manpower within the area under investigation could contribute to the poor water infrastructure maintainability.

\subsection{Site survey and erroneous design stage}

The site survey and design phases in water infrastructure management/maintenance involve the application of engineering techniques in determining the needed total pressure (dynamic head) to be overcome by the pumping system. This is found from the total static head $\left(\mathrm{H}_{\mathrm{s}}\right)$ and friction head loss, $\left(\mathrm{H}_{\mathrm{f}}\right)$ [5]. The first element of pressure depends upon site conditions in terms of location of water source and desired delivery point while the second relied on the pipe size and materials selected [1]. Also, the design involves the determination of installations/fittings necessary to supply the needed quality of water to the end user. Furthermore, locating the right source of supply [5] and installing the necessary water supply and distribution mains, branches and appurtenances on the water infrastructure are very essential [1].

In water quality distribution systems, management culture has been identified as one of the technical issues and gaps in institutional arrangements that inhibit solutions [4]. To plan for a befitting water production, storage and supply system, there is need for a geographical survey of the area or the existing master plan to be considered along with field testing, feasibility study and inspection to ascertain the existing structures and their viabilities. Enumeration must be carried out to establish the statistics of users, quality and quantity of water in demand. Water network modelling along with production in terms of borehole drilling, storage, and distribution analysis, leakages detection, metering programme must be taken into consideration $[5,1]$ with the aim of achieving the:

- Design of an appropriate water production, storage and distribution system that will meet the demand for a particular period of time;

- Size and type of water storage facilities needed; 
- Assessment of the existing water facilities for their viability, hence advising the facilities owner/managers on how to improve upon;

- Number of boreholes needed and the pump capacity required;

- Total head required for effective pressure at the fixtures and the

- Total volume of water needed on daily basis and to ensure availability on demand [5].

\section{MATERIALS SELECTION AND CONSTRUCTION METHODS}

Water storage stanchions can be made of precast concrete and steel materials vertically erected to raise the storage tanks [8]. Concrete, sometimes precast, pre-stressed tanks are widely used for underground tanks. The main reasons for water storage facilities are to raise pressure and conservation of water during peak demand [1]. Water can be pumped into the reservoirs (tanks) during periods of low demand and thereafter discharged into the distribution system during periods of peak demand. In addition, storage tanks can provide water pressure in the distribution systems.

Factors such as structural stability, equipment design, tank location, elevation, and capacity should all be taken into consideration. In many cases, water is stored in reservoirs on ground level $[1,10]$ in order to save cost of construction, maintenance and operation, ease for water quality test, safety and aesthetic value [2]. The primary disadvantage of a ground tank is inadequate water pressure. The optimal pressure in this reservoir can be maintained through directly pumping of water. The elevated tanks, on the other hand, have a major advantage of adequate pressure and discontinuous operation of pumps. The pressure of the water flowing out of an elevated tank is dependent on the depth of the water in the tank [5]. A nearly empty tank probably will not provide enough pressure while a completely filled tank may provide enormous pressure. The two common water infrastructure stanchions considered are: elevated concrete and steel. The materials used for the construction of SWS include: steel pipes, base plate, bolts, nuts and washers. It also involves steel plate, I-beam, steel bar, angle bars and paint [8]. Equally, cement, sand, gravel, reinforcement rods and water can be used in the construction of CWS [9]. The pictorial views of these stanchions from the studied areas are shown in Figures 1- 2 .

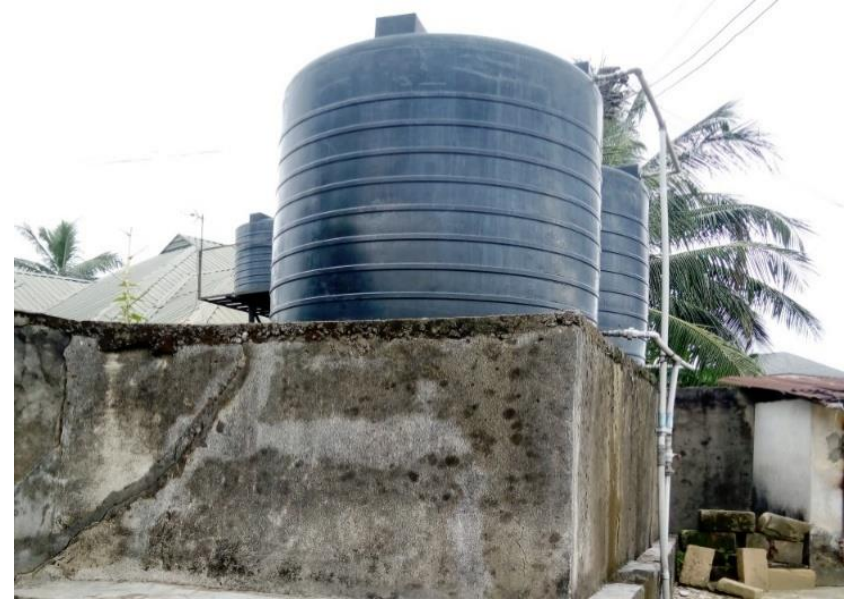

Figure 1: An elevated concrete water stanchion.

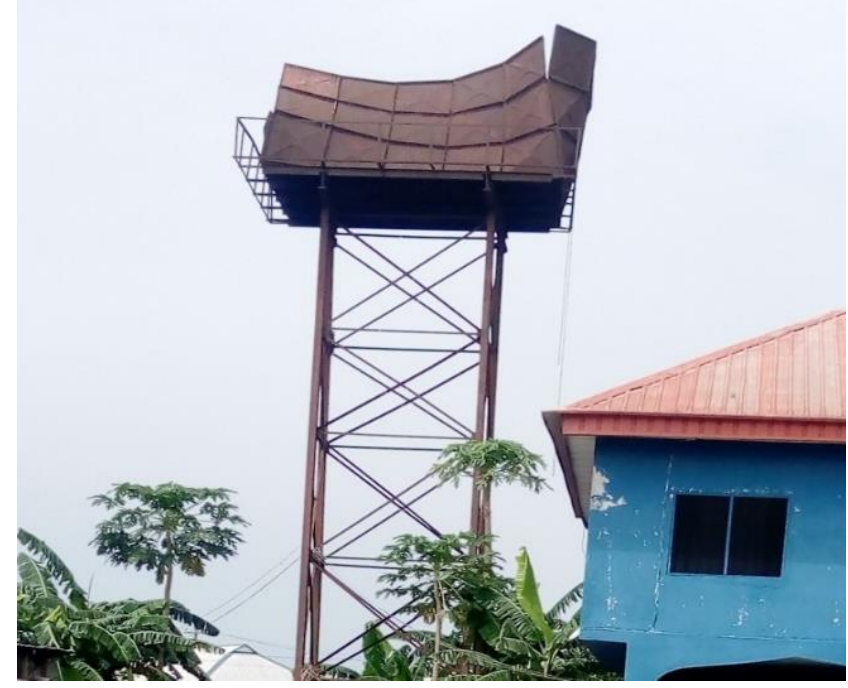

Figure 2: Elevated steel water stanchion.

\subsection{Clients' inclination in award of contract and use of unskilled manpower}

The predisposition of clients toward the award of contract for water infrastructure projects is a major concern in the built environment as many of them tend to influence the project execution by awarding water project(s), [8] to whoever they may wish against due professional considerations. However, dearth of experienced professionals and the use of quacks or unskilled personnel in the design and construction of water infrastructure are fundamental issues in the built environment that at times may lead to partial failure or outright collapse of the water infrastructure [10].

\subsection{Challenges}

Generally, people are under tremendous threats due to undesired global warming (challenges) within their environment [11]. Such environmental challenges include wind, microbiological growths/dark stains, paint deterioration, corrosion, air pollutants, air 


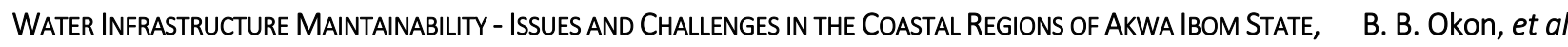

quality, moisture, rainfall [12], acidic rain, physiochemical parameters and heavy metals [13]. These threats also affect the physical infrastructure of water stanchions within the investigated areas.

\subsection{Microbiological growths, dark stains and paint deterioration}

Microbial growth in water depends on temperature, nutrient content and disinfectant concentration. In water network especially SWS, it will also depend on the composition of the internal pipe surfaces with an unpredicted effect [5]. The growth of microorganisms on paint layers may cause aesthetic and structural damage on the SWS. The aesthetic damage includes pigment discoloration, dark stain and formation of a biofilm on the painted surfaces of the steel. Structural damage on the other hand involves corrosion [6], cracking and disintegration of paint layers, paint blistering, and degradation of support polymers and binders resulting in detachment of the paint layer from the support. The deterioration of water stanchion infrastructure is a common problem in the built environment [11]. It is imperative to understand the factors and processes responsible for the defects and deterioration for proper management of the consequences [12]. The dark stain is as a result from chemical reaction between masonry in terms of concrete stanchions and the foreign matter which penetrates into the paints and masonry. The reason is that paint contains a wide range of organic and inorganic constituents and provides different ecological niches that may be exploited by a large variety of microbiological species. The biodegradation of additives is also a major concern as a result of stains formation on water facilities $[12,14]$.

\subsection{Environmental air pollutants}

Environment includes all the external factors influencing the life and activities of people, plants and animals [17]. Accordingly, it is the immediate surrounding in which the facilities operate. These include: air, water, land, flora and fauna, human beings, natural resources and the inter-relationship that exists between them. Our environment determines the well-being and existence, but man's activities destroy the natural quality of the environment (ecosystem), directly or indirectly, through impact, air pollution and over exploitation $[11,15]$. Air pollution occurs when there is contamination of air quality [22], that is, when air contains gases, dust, fumes, or odour in harmful amounts which can cause damage to ecosystem [15, 16]. Pollutants like sulphur dioxide, carbon monoxide, carbon dioxide, nitrate oxide, ozone, chlorofluorocarbons, and unburned hydrocarbons, volatile organic compounds, and other heavy metals are not only toxic but can cause air pollution some of which are emissions due to painting, torch cutting and welding operation processes of water infrastructure $[13,17,23]$.

\subsection{Moisture, rainfall and acidic rain}

Moisture can penetrate into the walls/surfaces of the stanchions and form rust, cracks, peels, discolourations, chalky dust and paints failure [13]. The problems are more prevalent in areas of high accumulation of moisture. Water vapour destroys the finished surfaces of water stanchions through diffusion process into the surfaces [24]. Rainfall as a precipitation process is considered significantly polluted and is usually dependent on the location of water infrastructure, industrial density, traffic intensity, prevailing winds season. Rain can acquire most of the particles and contaminants present in the atmosphere, such as solids, traces of heavy metals and particles [19]. For instance, the products of incomplete combustion such as nitrogen oxide $\left(\mathrm{NO}_{2}\right)$ and nitrogen monoxide (NO) are toxic to the environment. These, along with chlorides in the air dissolved into rain and form acid rain. This rain can be directed to the walls (surfaces) of the water stanchions by wind which in turn can cause dark stains or corrosion as the case may be from acidic rain after exposure up to a pH level of less than 5.6, [13].

\subsection{Corrosion}

Salt hastens the corrosion process of metals and disrupts the crystal lattices of SWS $[9,20]$. Corrosion is an attack on metallic materials as a result of environmental reactions. Equally, it is the deterioration of materials as a result of external factors such as water, humidity and weather condition [21] on water stanchions. The corrosion of metals is essentially an electrical conductance phenomenon either oxidative, where oxygen is the oxidant or galvanic, where a dissimilar metal is the oxidant. Wet corrosion is the type where the corrosive environment is water with dissolved species, the liquid is an electrolyte and the process is typically electrochemical. Alternatively, dry corrosion is the form where the corrosive environment on SWS 
is a dry gas [21]. Corrosion does not simply start at some minimum level of salinity; a sliding scale of increased risk occurs with a complex interaction of exacerbating factors. The propensity of corrosion may also be influenced by the potential hydrogen of liquid content on water stanchion. An electrical current (EC) study can be applied to interpret the impact of salinity (indicative salinity risk) on water infrastructure stanchions $[6,23]$.

Inferably, the aggression toward concrete is not dependant on electrical conductance but on the types of ionic substances such as $\mathrm{Cl}$ and $\mathrm{SO}_{4}$. Different ions will cause either an expansive change or a loss of cementitious properties thus, affecting the strength of the concrete. Permeability of the CWS itself to air and moisture is the overriding factor influencing the durability/resistance of CWS to chemical attack [9]. The degradation in CWS such as spalling due to mechanical stresses within the concrete, results from the formation of expansive salts within the matrix of the concrete. Generally, while CWS will slowly abate as a result of salt rise and mechanical disruption of structure, SWS on the other hand will slowly oxidize even in the atmosphere $[20,24]$.

\section{METHODOLOGY}

The method according to [23] was employed to investigate the indicative salinity risk to water infrastructure and the results were insightful and indicated a mild and increasingly rapid aggression and corrosion on the stanchions [6]. Also, physiochemical and elemental analyses on rain water were performed by [13] to determine its effects on roofing materials with significant impact of heavy metals on the material.

In this work, samples were collected from four affected water infrastructure for laboratory tests. The obtained data from the affected locations were analysed in the laboratory for analytical purposes. Standard analytical procedures were adopted for the tests, analysis and characterisation of the identified issues/challenges [6]. The concentration levels of heavy metals, physiochemical parameters, air quality and water quality were examined. The physiochemical parametric analysis investigates both the physical and chemical properties of the samples. Contextually, these parameters include: potential hydrogen, water temperature, chemical oxygen demand, dissolved oxygen and electrical conductivity. Also, nitrate, phosphate, sulphate, total dissolved solids (TDS) and total organic content (TOC) were analysed. Total suspended solids (TSS), turbidity, smoke, humidity, pressure and wind direction/speed were as well investigatef $[6,15,19]$. Other applicable methods in this study are as presented.

\subsection{Electrical conductivity}

This study became necessary as the electrical conductivity (EC) is a numerical expression of the ability of an aqueous solution to carry electric current. This depends on the presence of ions, their total concentration, mobility, valence and relative concentrations and temperature. The electrical conductivity is measured in $\mathrm{dS} / \mathrm{m}$, [26].

\subsection{Nitrate}

Nitrate $\left(\mathrm{NO}_{3}\right)^{-}$is the most highly oxidized form of nitrogen compounds commonly present in natural water because it is a product of aerobic decomposition of organic nitrogenous matter. Significant sources of nitrates are fertilizers, decayed vegetable and animal matter, domestic and industrial effluents and atmospheric washouts. The high concentration of nitrate in water is an indication of pollution. The intensity of colour produced is directly proportional to the concentration of nitrates, measured with UV-Spectrophotometer. Sources of nitrate ions include; municipal and industrial wastewater; automobile and industrial emissions and decomposition of plants and animals. As such, nitrate in $\mathrm{mg} / \mathrm{kg}$ or $\mathrm{mg} / \mathrm{l}$ was evaluated as shown in eqn. (1), $[26,27]$.

Nitrates $=\frac{\text { Absorbance of sample } \mathrm{x} \text { conc. of standard } \mathrm{x} 1000}{\text { Absorbance of standard } \mathrm{x} \text { sample taken }}$

\subsection{Phosphate}

In this analysis, phosphorus is a fundamental element in the metabolic reaction. It controls the growth and productivity of algae. Excess amounts of phosphorus can cause eutrophication leading to algal blooms and can be considered a pollutant. High level of phosphate leads to eutrophication; increased algal blooms; increased biochemical oxygen demand (BOD); decreased dissolved oxygen (DO). Low levels of phosphate limit plant and algal growth. Phosphate $\left(\mathrm{PO}_{4}\right)^{3-}$ in $\mathrm{mg} / \mathrm{kg}$ or $\mathrm{mg} / \mathrm{l}$ was computed as presented in eqn. (2), [26, 27].

$$
P=\frac{\text { Absorbance of sample } \mathrm{x} \text { conc. of standard } \mathrm{x} 1000}{\text { Absorbance of standard } \mathrm{x} \text { sample taken }}
$$




\subsection{Potential hydrogen}

The potential hydrogen $(\mathrm{pH})$ of a solution is the measure of the molar concentrations of the hydrogen ions in the solution. $\mathrm{pH}$ measures the acidity, the neutrality and the basicity of a solution. In this context, the $\mathrm{pH}$ value of water is determined by the relative concentrations of $\mathrm{H}^{+}$ion and $\mathrm{OH}^{-}$ions [26]. The $\mathrm{pH}$ scale commonly ranges from zero to fourteen along logarithmic scale with values less than seven indicating acidity; neutral solution, at the value of seven meaning the solution has equal concentrations of $\mathrm{H}^{+}$ion and $\mathrm{OH}^{-}$ions and values above seven indicating basicity, meaning the concentration of $\mathrm{H}^{+}$ ion is less than the concentration of $\mathrm{OH}^{-}$ion in such solution. Levels between 6.5 and 8.5 are acceptable for most drinking water standards. Water produced from rainfall generally has a $\mathrm{pH}$ value between 5 and 6.5. It is acidic because of dissolved carbon dioxide and air pollutants such as sulphur dioxide or nitrogen oxides. If rainwater flows over soil containing hardwater minerals, its pH usually increases [27].

\subsection{Salinity}

Salinity from this study measures the total salt concentration, comprising mostly of sodium and chloride ions as well as small quantities of other ions from magnesium, potassium and sulphate. In drinking water, the test for salinity determines the concentration of chloride ion in the sample. Consequently, high concentration of salt in water results in corrosion of the surface of its storage facility, in this case, water stanchions. Salinity in water was studied in $\mathrm{mg} / \mathrm{kg}$ or $\mathrm{mg} / \mathrm{l}$ as shown in eqn. (3), [26].

$$
\text { Salinity }=\frac{\mathbf{V}_{\mathbf{2}} \times \mathbf{E} \times \mathbf{N} \times \mathbf{1 0 0 0}}{\mathbf{V}}
$$

Where; $V=$ Volume of sample, $V_{2}=$ Volume of $\mathrm{AgNO}_{3}, \mathrm{E}=$ Equivalent weight of $\mathrm{NaCl}, \mathrm{N}=$ Normality of $\mathrm{AgNO}_{3}$.

\subsection{Sulphate}

Sulphate was examined and this can be found in all natural waters particularly those with high salt content. Besides industrial pollution and domestic sewage, biological oxidation of reduced sulphur species also adds to sulphate content. Sulphate causes scaling, odour and corrosion in water supply infrastructure as a result of reduction to hydrogen sulphide. It was calculated by turbidometric method in $\mathrm{mg} / \mathrm{kg}$ and $\mathrm{mg} / \mathrm{l}$ for dry and wet samples respectively as presented in eqn. (4), [26].
Sulphate $=\mathrm{N} \times 0.4 \mathrm{df}$

Where; $\mathrm{N}=$ Nephlometric reading, $\mathrm{df}=$ dilution factor.

\subsection{Total dissolved solids}

The total dissolved solids (TDS) was evaluated in this study and is expressed as solids that are in dissolved state in a solution [25]. They are the total amount of mobile charged ions, including minerals, salts or metals dissolved in a given volume of water measured. TDS in $\mathrm{mg} / \mathrm{kg}$ and $\mathrm{mg} / \mathrm{l}$ for dry and wet samples respectively was analysed as shown in eqn. (5), [26, 27].

$$
T D S=\frac{W_{2}-W_{1} \times 10^{3}}{\text { Volume of Sample }}
$$

\subsection{Total suspended solid}

This study also investigated the total suspended solid (TSS). In this case, TSS is the total quantity of solid material per volume of water. Also, it is the total portions of solids that do not settle. The total suspended solids are particles that are larger than two microns found in water column. Anything smaller than two microns is considered a dissolved solid [13, 25]. Organic particles from decomposing materials can also contribute to the TSS concentration. The effect of the presence of TSS is turbidity due to organic matter. TSS measured in $\mathrm{mg} / \mathrm{kg}$ and $\mathrm{mg} / \mathrm{l}$ for dry and wet samples was calculated as presented in eqn. (6), [26, 27].

$$
T S S=\frac{W_{2}-W_{1} \times 10^{3}}{\text { Volume of sample }}
$$

Where; $W_{2}=$ Constant weight of filter paper + sample

\subsection{Turbidity}

Turbidity measures the clarity of water. It is an expression of the optical property where light is scattered by suspended particles present in water and was measured using nephelometer [25]. The effects of turbidity include the reduction of water clarity, unpleasant aesthetics, and decrease in rate of photosynthesis with increase in water temperature. High turbidity decreases the amount of sunlight penetrating the water thereby decreasing the rate of photosynthesis [26]. The turbidity of surface water is between 1 and 50 NTU and the standard for drinking water is $0.5-1.0 \mathrm{NTU}$. Turbidity can be determined as indicated in eqn. (7), [27]. 
Table 1: Rain water results from the studied water stanchions.

\begin{tabular}{llll|lll}
\hline Factor & \multicolumn{2}{c}{ SWS } & \multicolumn{3}{c}{ CWS } \\
\hline & I & II & III & I & II & III \\
$\mathrm{pH}(-)$ & 5.6 & 5.4 & 5.3 & 6.1 & 5.9 & 6.0 \\
$\mathrm{~T}\left({ }^{\circ} \mathrm{C}\right)$ & 29.8 & 29.1 & 28.8 & 28.7 & 29.0 & 28.6 \\
$\mathrm{EC}(\mathrm{dS} / \mathrm{m})$ & 36 & 34 & 38 & 30 & 29 & 28 \\
$\mathrm{TDS}(\mathrm{mg} / \mathrm{l})$ & 20 & 14 & 11 & 23 & 17 & 15 \\
DO $(\mathrm{mg} / \mathrm{l})$ & 1.8 & 1.7 & 1.5 & 2.0 & 1.9 & 1.7 \\
Turb. $(\mathrm{NTU})$ & 1.5 & 1.2 & 1.1 & 1.4 & 1.2 & 1.4 \\
\hline
\end{tabular}

Table 2: Air quality results from the studied water stanchions.

\begin{tabular}{llll|lll}
\hline Factor & \multicolumn{3}{c}{ SWS } & \multicolumn{3}{c}{ CWS } \\
\hline & I & II & III & I & II & III \\
T $\left.{ }^{\circ} \mathrm{C}\right)$ & 28.6 & 28.5 & 28.2 & 28.2 & 28.5 & 28.8 \\
RH $(\%)$ & 82.0 & 82.1 & 81.2 & 82.4 & 82.0 & 82.3 \\
Smoke & 0 & 0 & 0 & 0 & 0 & 0 \\
Pressure, $\left(\mathrm{N} / \mathrm{mm}^{2}\right)$ & 10.0 & 10.0 & 10.0 & 10.0 & 10.0 & 10.0 \\
WD & SE & SE & SE & SE & SE & SE \\
WS $(\mathrm{N} / \mathrm{m})$ & 2.1 & 1.8 & 1.4 & 1.9 & 2.2 & 1.6 \\
Air Flow & Calm & Calm & Calm & Calm & Calm & Calm \\
Noise $(d)$ & 53.9 & 53.7 & 48.2 & 52.7 & 49.0 & 48.2 \\
SPM & 5 & 6 & 7 & 6 & 8 & 8 \\
CO & 0 & 0 & 0 & 0 & 0 & 0 \\
$\mathrm{H}_{2} \mathrm{~S}$ & 0 & 0 & 0 & 0 & 0 & 0 \\
\hline
\end{tabular}

NTU $=$ Nephelometer readings $x \mathrm{df} \quad--\quad$ (7) Where, $\mathrm{df}$ is the degree of freedom of the investigated stanchions

\section{RESULTS AND DISCUSSIONS}

The analyses from the achievable results are presented in Tables 1-2.

In Table 1, it is evident that the $\mathrm{pH}(-)$ results are higher in the investigated CWS than SWS except the turbidity results which are somewhat at par in this case. The outcomes indicate some significant variations in TDS which are more prevalent on the CWS within the investigated environment. Conversely, TDS can cause more damage on the CWS than SWS vis-à-vis the rain water analysis over a period of time after commissioning and use. However with its exception, all other factors within this range showed substantial evidences at proximate intervals. Results from Table 2 indicate slight variations in the wind speed $(\mathrm{N} / \mathrm{m})$ and noise within the investigated CWS than SWS; however, other tested parameters yielded almost equivalent results. This expresses the fact that both stanchions are stable during wind blast and the analysed factors do not have negative impact on them. The results from other tested factors did not show major variations. On this premise, it points to the fact that steel stanchions are susceptible to thermal expansion when exposed to high temperature over concrete. From this study also, installation of the necessary water supply and distribution mains, branches and appurtenances on the water infrastructure are very essential but priority attention is on periodic maintenance of the water facility. It is however adduced from this study that continuous (periodic) and practical maintenance culture is a panacea, for effective water infrastructure sustainability. This study further established better ways of tackling these problems which are indicative risks concerning maintainability of water infrastructure for optimum service delivery as indicated in Figures 1 and 2.

\section{CONCLUSION}

The major issues and challenges regarding water infrastructure maintainability within the study area have been identified. Standard analytical methods employed in testing the collected samples measured 
the variable impacts on the water infrastructure. Accordingly, better ways of addressing the identifiable risks concerning maintainability of water infrastructure have been established for optimum service delivery. These results would be useful for stakeholders within the built environment for consideration during the design, planning, construction, operation and maintenance phases of water stanchions and the associated appurtenances. Based on the investigation results, it would be of utmost importance during water infrastructure design, construction and maintenance to allow overflow sprout of rain barrel to be directed away from the walls and foundations of water stanchions; this is to avert seepage on the stanchions. Practically, all openings on the walls that could allow air and liquid ingress should be sealed. Steel stanchion made of aluminium alloy or aluminium material is preferred to concrete stanchion due to its non-corrosive tendency, simplicity in construction, lightness in weight and durability.

Apart from the above highlights, the study also shows that, non-return control valves should be provided at the inlet of the reservoir to avoid backfill. Then, centrifugal pumps should be used to discharge water from the source because of its cost effectiveness, efficiency and availability. However, where booster pumps are required, submersible pumps may be used as back-ups. Similarly, when laying unplasticized polyvinyl chloride (UPVC) pipes, the trench bottom should be free from sharp stones and the back filling sand (soil) be brought up evenly to prevent distortion of pipes and for ease of maintenance when need arises. Water by-laws should be imposed in the area under review with the aim of checkmating defaulters thus, maintaining standard. Other infrastructure should not be built along water network right-of-way to avoid damages on the water systems. From this study, data obtained and analysed using the Ministry of Science and Technology laboratory, Uyo, are reliable given the fact that this laboratory is of international standard and is well-known for providing accurate information on the studied factors.

\section{ACKNOWLEDGEMENTS}

The authors acknowledge the invaluable support and cooperation of the management and staff of the Ministry of Science and Technology, Uyo, Akwa Ibom State, Nigeria during the course of this research. In addition, the owners of the water infrastructure within the study area are equally appreciated.

\section{REFERENCES}

[1] Okon, B. B. and Okon V. E. "Building services equipment and effective maintenance culture: the experts' standpoint", Journal of mechanics engineering and automation, Vol. 8, 2018, pp 35-42.

[2] Dey, K., Mohapatra, S. C. and Misra, B. "Assessment of water quality parameters of the River Brahmani, Rourkela", Journal of industrial pollution control, Vol. 21, Number 2, 2005, pp 299-304.

[3] Elmualim, A., Vale, R. and Kwawu, W. "Discerning policy and drivers for sustainable facilities management practice", International journal of sustainable built environment, Vol. 1, 2012 pp 16-25.

[4] Griggs, N. S. "Institutional analysis of infrastructure problems: case study of water quality in distribution systems", Journal of management in engineering, Vol. 22 Number 4, 2005, pp 152-158.

[5] Chambers, K., Creasey, J. and Forbes, F. Design and operation of distribution networks, IWA Publishing, London, 2004.

[6] Simon, L. Salinity and structures: measurement and interpretation of results, Pty Itd, Thornleigh, 2017.

[7] Ite, A. E., Ubong, U. U., Etesin, U. M., Nsi, E. W., Ukpong, E. J., Ekanem, A. N., Ufot, U. F. and Udo, I. U. "Heavy metals in epiphytic lichens and mosses of oil producing communities of Eket and Ibeno, Akwa Ibom State, Nigeria", American Journal of Engineering Protection, Vol. 4 Number 2, 2016, pp 38-47.

[8] Ademiliyi, I. A. "Public housing delivery strategies in Nigeria: a historical perspective of policies and programmes" Journal of Sustainable Development in Africa, Vol. 12, Number 6, 2010, pp 153 - 161. ISSN: 1520-5509.

[9] Albert, K., Kwan, Henry, H. and Wong, C. Durability of reinforced concrete structures (Theory and practice), Department of Civil Engineering, University of Hong Kong, 2007.

[10] Dana, S., Investigating the Durability of Structures. Postgraduate Thesis, MIT, 2013. http://.handle.net/1721.1/82718, Accessed: on June 22, 2019.

[11] "Our Common Future", World Commission on Environment and Development (WCED), Brundtland Report, Session A (42), 1987, p 427, Oxford University Press. ISSN 019282080X. 
[12] Nada, F. N., Bakri, O. and Mydin, A. O. "General building defects: causes, symptoms and remedial work", European Journal of Technology and Design, Vol. 3, 2014, pp 5-9.

[13] Oboh, A. E, Agwu, O. and Umana, M. "Discolouration of aluminium roofing sheets in Uyo, Nigeria", International Journal of Science and Engineering Investigations, Vol. 6, Number 60, 2017, pp 73-79.

[14] Ransom, W. H. Building failure - diagnosis and avoidance, $2^{\text {nd }}$ ed. Routledge Publishers, New York, 1987.

[15] Cheshire, D. and Maunsell F. Introduction to sustainability. Chartered institution of building services engineers, ASHRAE Guide, 2007.

[16] Roux, C. and Peuportier, B. "Evaluation of the environmental performance in buildings using dynamic life cycle simulation", Proceeding of BS2013, the $13^{\text {th }}$ Conference of International Building Performance Simulation and Association, Chambery, France, August 26-28, 2013.

[17] Chris, R. and Emily, F. Your home, Australian Guide to Environmental Sustainable Home, 2003.

[18] Guggeemos, A. A. and Horvath, A. "Comparison of environmental effects on steel and concrete as construction materials", Journal of infrastructure systems, Vol. 11, Issue 2, 2005, pp 93-101.

[19] Jacobson, M. "Review of solution to global warming, air pollution, and energy security",
Journal of Energy and Environmental Science, Vol. 2, Number 2, 2009.

[20] Neville, A. M. Properties of Concrete, $4^{\text {th }}$ ed., Longman, England, 1995.

[21] Metals Handbook - Fractography, $9^{\text {th }}$ ed., Vol. 1, American Handbook Committee, ASM International, Ohio, 1987.

[22] Wark, K and Warmer, C. F., and Davis, W. T. Air pollution: origin and control, $3^{\text {rd }}$ ed., Addison Wesley, 1998.

[23] Umali, D. L. "Irrigation induced salinity: a growing problem for development and the environment", World Bank technical paper, Number WTP 215, Washington DC., 1993.

[24] Bujnak, J. "Environmental impact of steel and concrete as building materials on the global environment", Proceedings of post gradual course on building efficiency, Novi Pazar, 14-15 February 2011, pp 2 - 34.

[25] Adekunle, A. "Removal of heavy metals from industrial effluents by water hyacinth (Eichornia crassipes) ", Journal of Environmental Chemistry and Ecotoxicology Vol. 4, Number 11, 2012, pp 203-211.

[26] Baird, R. B., Eaton, A. D. and Rice, E. W. Standard methods for water and wastewater examination, $20^{\text {th }}$ ed., American Public Health Association (APHA), Washington D. C., 1988.

[27] Walter, G. W. Standard Methods for water and wastewater Examination, American Journal of Public Health and the Nation's Health, $11^{\text {th }}$ ed., Vol. 51, Number 16, American Public Health Association, Washington D. C., 2011. 